\title{
AN ANALYSIS OF DISCOURSE MARKERS IN THE ARTICLES ON HAMLET DRAMA WRITTEN BY ENGLISH EDUCATION STUDENTS AT UNIVERSITY OF MATARAM
}

\author{
Frida Anjani Hidayat ${ }^{1}$, Baharuddin $^{2}$, Muh. Isnaini ${ }^{3}$ \\ ${ }^{123}$ English Education Department, Faculty of Teacher Training and Education, \\ University of Mataram, Indonesia \\ *Corresponding Author's: bahar@unram.ac.id
}

\begin{abstract}
This study is targeting at portraying the sorts and the errors of discourse markers made in the articles on Hamlet drama composed by the 6th semester students of English education program at University of Mataram in the academic year 2019/2020. The technique of conducting this investigation is a blended strategy or mix of qualitative and quantitative techniques. The data were gathered from 26 students' articles. The result of this study showed that all the types in three functional classes of discourse markers by Bruce Fraser (2009) were used by students in their articles. They are Elaborative Discourse Markers with total number of occurrences 200 times (43.20\%), Contrastive Discourse Markers with total number of occurrences 169 times (36.50\%), and Inferential Discourse Markers with total number of occurrences 94 times $(20.30 \%)$. The researcher found that Elaborative Discourse Markers are most frequently employed by students to elaborate the ideas. Furthermore, there are some errors in student's articles related to Kao and Chen's theory (2011) about the six types of misuse patterns. Turns out three of six misuse patterns occur in students' articles such as distraction, wrong relation, and semantic incompletion. There are no surface logicality, nonequivalent exchange, and overuse occurred in students' articles.
\end{abstract}

Keywords: discourse markers; articles; writing

\begin{tabular}{l}
\hline Received: Nov 4, $2021 \quad$ Accepted: Nov 16, $2021 \quad$ Published: Dec 31, 2021 \\
\hline How to cite (in APA style): \\
Hidayat, F. A., Baharuddin, \& Isnaini, M. (2021). An analysis of discourse markers in the articles \\
on hamlet drama written by English education students at University of Mataram. JEEF \\
(Journal of English Education Forum), 1(2), 1-6.
\end{tabular}

\section{INTRODUCTION}

English is an important language that everyone should know and learn because it is the greatest common language spoken universally and used for international communication. Since, English as a language is important to communicate for daily life. All students should master the four skills of English such as listening and reading as receptive skills and speaking and writing as productive skills.

Writing skill has a very important role because it is used and needed, especially in more professional fields such as high school, college, or work. Writing is necessarily needed because through writing every person could express thought or feelings, increase critical thinking, or create brilliant ideas. As claimed by Brown (2001:348) "Writing is a thinking process, because writing is a process of putting ideas down on paper to transform thought into words and give them structure and coherent organization" To produce good writing, people not only pour all the critical thoughts but also pay attention to the writing structure. Briefly, it would be difficult for some people to produce good writing without learning the language skills.

Writing is something that students must do. In higher education the students learn, and use essay for several subjects. Generally, an essay is a writer's perspective or story which is outlined in text form. An essay can be formal and informal. Writing Essay is not just 
focused on how to create brilliant ideas and put it into the text or to arrange the text coherently and cohesively, but also it is important to pay attention to the use of discourse markers.

Discourse markers are absolutely necessary to complete effective writing and as a support to produce coherent and cohesive paragraphs. According to Fakuade and Sharudama (2012:300-318) discourse markers are the lexical expressions that are used to connect ideas between sentences so that it could construct the flow of discourse. They are really helpful to define related text ideas. From that, in simpler terms, discourse markers are useful to make sure that sentences are related to one another, so the reader can easily understand the contents of the writing. In addition, Fraser (2009:296) claims that discourse markers are divided into three functional classes, such as Elaborative Discourse Markers, Contrastive Discourse Markers, and Inferential Discourse Markers.

Discourse markers become an important thing and must be in a paragraph to produce a good essay. This is the obligation of students to master discourse markers itself to write effectively. However, the problem is that many students still find it difficult and confused to use appropriate discourse markers to connect and organize sentences. Despite the many variations of discourse markers in each class, students sometimes still use the same variations. They choose a safe way to use primary discourse markers such as but, and, so, etc. Not frequently, there are still many students who lack accuracy, misinterpret, and misplace a DMs in inappropriate sentences.

Regarding the information about the use of discourse markers in student articles, this research is aimed at investigating 1) the types of discourse markers used in the articles, and 2) the errors in using discourse markers in the articles on Hamlet drama.

\section{RESEARCH METHOD}

This research used a mixed method or combination of qualitative and quantitative methods. The mixed method in this study is used to provide a better understanding of the research problems. A qualitative method refers to the description of errors of discourse markers that found in the articles on Hamlet drama composed by 26 students of sixth semester of English Education Program at University of Mataram in the academic year 2019/202. Meanwhile, a quantitative method used to show the types of discourse markers that occurs in the articles on Hamlet drama in a number.

In this research, in order to investigate the use of discourse markers in the students' articles in the form of exposition/expository articles related to Hamlet drama, the researcher collects the data through a documentation method. In conducting this method, the researcher provides documents, books, etc.

The data are collected through several steps. First, the researcher collected the articles from 28 students who have completed the Drama course's final assignment. Then, the researcher read the entire articles. After that, the researcher highlighted the markers and the errors that appear on the articles. All highlighted markers and errors are noted. In addition, all the markers that have been noted are categorized by entering into the table that has been created by the researcher. Before the researcher input the data into the table analysis, the researcher found out the percentages by using the formula as follows: 


$$
\mathrm{P}=\frac{f}{N} \times 100 \%
$$

$\mathrm{P}=$ Percentage of the results

$\mathrm{f} \quad=$ Frequency of each type/variant discourse markers that used by the students

$\mathrm{N}=$ Total amount the data

In order to find out the result of this research, the researcher uses a table of analysis based on the three functional classes of discourse markers by Fraser's (2009) theory. The function of this table analysis is to classify the data. In this table include the number of occurrences of each variant for each type of discourse markers to show the result of the frequency of discourse markers that students used in their articles.

The data in this research were analyzed in the following procedures. First, identifying the types of discourse markers and errors in the essay writing. After that, classifying the types of discourse markers based on Fraser's three functional classes theory by entering the data into the table analysis that has been created. Also, classifying the errors that found in the essay writing based on Kao and Chen's (2011) theory. Then, describing the types of discourse markers and the errors found in the essay writing. The last step is concluding the results of the data analysis in related to research questions and purposes of the study.

\section{FINDINGS AND DISCUSSION}

According to the data finding which was obtained through the methods in this research, the researcher found that, there are three types of discourse markers that students used in their articles such as Elaborative, Contrastive, and Inferential Discourse Markers. Students used each type of discourse markers according to the context or sentences they write. Moreover, the researcher also found that based on Kao and Chen (2011) theory, there are six types of misuses pattern such as non-equivalent exchange, overuse, surface logicality, wrong relation, semantic incompletion, and distraction. The researcher found that from the six misuse patterns, there were several that appeared in students' articles such as distraction, wrong relation, and semantic incompletion. The findings are discussed in the following section below.

Based on the findings above, to answer the first research question, the researcher used Fraser's (2009) three functional classes of Discourse Markers theory and also used a table to present the data. It showed that there are three types of Discourse Markers that appear in students' articles such as Contrastive, Elaborative, and Inferential Discourse Markers.

Table 1. Discourse Markers Used in Students Essay

\begin{tabular}{|c|c|c|c|c|}
\hline No. & $\begin{array}{l}\text { Types of Discourse } \\
\text { Markers }\end{array}$ & Variants of Discourse Markers & $\begin{array}{l}\text { Number of } \\
\text { Occurrences }\end{array}$ & Percentage \\
\hline 1. & Elaborative Markers & $\begin{array}{l}\text { And, Also, In addition, For example, In other } \\
\text { words, Or, Furthermore, Moreover, For instance. }\end{array}$ & 200 & $43.20 \%$ \\
\hline 2. & Contrastive Markers & But, Although, However, On the other hand, Yet. & 169 & $36.50 \%$ \\
\hline \multirow[t]{2}{*}{3.} & Inferential Markers & So, Then, Therefore, Thus, Because (of this/that). & 94 & $20.30 \%$ \\
\hline & Total & & 463 & $100 \%$ \\
\hline
\end{tabular}




\section{The Use of Elaborative Discourse Markers}

The most common type of discourse markers in students' articles is Elaborative Discourse Markers with total of occurrences 200 times. The researcher found that this type of Elaborative Discourse Markers was used by the students in their articles to elaborate the ideas or add information that is represented by the prior segment. Among all the variants of Elaborative Discourse Markers, markers and were mostly used by the students in their essay to connect the sentences, add more explanations, or give examples to the next segment to support the statement that has been written in the prior segment. In other words, the students' used this type of marker in their articles to signal continuity. Those data detail can be seen follows:

Table 2. The Use of Elaborative Discourse Markers

\begin{tabular}{llll}
\hline No. & Elaborative Markers & Number of Occurrences & Percentage \\
\hline 1. & And & 127 & $27.43 \%$ \\
2. & Also & 8 & $1.73 \%$ \\
3. & In addition & 23 & $4.97 \%$ \\
4. & For example & 3 & $0.65 \%$ \\
5. & In other words & 4 & $0.86 \%$ \\
6. & Or & 17 & $3.67 \%$ \\
7. & Furthermore & 8 & $1.73 \%$ \\
8. & Moreover & 5 & $1.08 \%$ \\
9. & For instance & 5 & $1.08 \%$ \\
\hline \multicolumn{2}{l}{ Total } & 200 & $43.20 \%$
\end{tabular}

\section{The Use of Contrastive Discourse Markers}

Contrastive Discourse Markers in students' articles occupy the second position for the most use of discourse markers after elaborative discourse markers with the number of occurrences up to 169 times. The students used this type of marker is to signal that the explicit interpretation of the next segment contrasts with an interpretation of the previous segment. In other words, this type is used to contrasting the idea. Among all variants of contrastive discourse markers, marker but was mostly used by the students to contrast the ideas in their articles because it's more familiar, simpler, and easy to use. Those data detail can be seen follows:

Table 3. The Use of Contrastive Discourse Markers

\begin{tabular}{llll}
\hline No. & Contrastive Markers & Number of Occurrences & Percentage \\
\hline 1. & But & 107 & $23.11 \%$ \\
2. & Although & 18 & $3.89 \%$ \\
3. & However & 30 & $6.48 \%$ \\
4. & On the other hand & 7 & $1.51 \%$ \\
5. & Yet & 7 & $1.51 \%$ \\
\hline \multicolumn{2}{l}{ Total } & 169 & $36.50 \%$ \\
\hline
\end{tabular}




\section{The Use of Inferential Discourse Markers}

Inferential Discourse Markers are the least discourse markers used by the students' essay. It's only occurred about 94 times. Mostly the students used inferential Discourse Markers in the initial and medial segment in the sentences. This type of marker is used by the students to signal that the next segment taken as a conclusion or result based on the previous segment. In students' articles, this type is the one that appears the least in articles compared to other types. Because usually, students only use this variant of discourse markers in the conclusion section to conclude or summarize the topics that they discuss. Those data detail can be seen follows:

Table 4. The Use of Inferential Discourse Markers

\begin{tabular}{llll}
\hline No. & Inferential Markers & Number of Occurrences & Percentage \\
\hline 1. & So & 30 & $6.48 \%$ \\
2. & Then & 22 & $4.75 \%$ \\
3. & Therefore & 11 & $2.38 \%$ \\
4. & Thus & 18 & $3.89 \%$ \\
5. & Because (of this/that) & 13 & $2.80 \%$ \\
\hline \multicolumn{2}{l}{ Total } & 94 & $20.30 \%$ \\
\hline
\end{tabular}

\section{The Types of Errors in the Use of Discourse Markers}

Based on the findings, in order to find the errors in the students' articles, the researcher used Kao and Chen (2011) theory that consisting of six type of misuse patterns. The researcher found that there are three of six types of errors in the use of discourse markers in students' articles such as (1) distraction, means that the context of the sentence can be coherent without the use of the discourse markers. It is often found that students use the discourse markers redundantly, (2) Wrong Relation, this pattern of misuse of discourse markers is an incorrect relationship shown in the student's writing as a result of the student's failure to use appropriate discourse markers to express certain textual relationships, (3) Semantic incompletion is where the discourse markers used by students lacks elaboration, the students need more elaboration to make the discourse markers functional.

\section{CONCLUSION}

The findings and discussion on the use of discourse markers conclude two main points. First, it is found that all the types in three functional classes of discourse markers by Bruce Fraser (2009) were used by students in their articles. They are Elaborative Discourse Markers (43.20\%), Contrastive Discourse Markers (36.50\%), and Inferential Discourse Markers $(20.30 \%)$. The researcher found that among three types of discourse markers that used by the students, the types of Elaborative Discourse Markers were most frequently used to elaborate the ideas with the total of occurrences 200 times (43.20\%). Second, in the case of errors that occurs in students' articles, it is found that based on Kao and Chen theory (2011) about the six types of misuse patterns, there are three of six misuse pattern that occurs in students' articles such as distraction, wrong relation and semantic incompletion. Further, it can be concluded that there are some students who still found it difficult to use discourse markers appropriately. 


\section{REFERENCES}

Brown, H. D. 2001. Teaching by principle: An interactive approach to language pedagogy (2nD Edition). New York: Addison Wesley Longman

Fakuade, G., \& Sharudama, E. C. 2012. A comparative analysis of variations in cohesive devices in professional and popularized legal texts. British Journal of Arts and Social Sciences, 4(2), 300-318.

Fraser, B. 2009. An Account of Discourse Markers. International review of pragmatics 1 (2), 293-320.

Kao, T., \& Chen, L. 2011. Diagnosing Discoursal Organization in Learner Writing via Conjunctive Adverbials. ROCLING 2011 Poster Papers, 310-322. 